\title{
外来杂草在我国的危害性及其管理对策
}

\author{
强 胜 \\ (南京农业大学杂草研究室, 南京 210095) \\ 曹学章
}

( 国家环境保护总局南京环境科学研究所, 南京 210042)

摘要 : 外来杂草已对我国的农作物生产、果园、草坪、环境和生物多样性等造成了严重危害。外来杂草之所以能在 传入地产生危害, 与它们所具有的某些特性和当地缺乏环境阻力密切相关。对外来杂草的管理应从防止外来杂草 传入和对现有的外来杂草实施防除两方面采取措施。防止传入的措施包括: (1) 加强植物检疫; (2) 建立外来植物 引种驯化的风险性评价制度; ; 鼓励利用本土植物。对现有外来杂草的防除,则应采取综合性的防除措施: (1) 防 治生态破坏; ; (2) 开展外来杂草的生物控制; (3) 利用经济植物进行生境替代控制; (4) 开展对外来杂草的利用。

关键词 : 外来杂草, 危害, 杂草管理, 对策

中图分类号: S451.1 文献标识码:A 文章编号 : 1005-0094(2001)02-0188-08

\section{Harmfulness of exotic weeds in China and for their management}

QIANG Sheng ${ }^{1}$, CAO Xue-Zhang ${ }^{2}$

1 Weed Research Laboratory, Nanjing Agricultural University, Nanjing 210095

2 Nanjing Institute of Environmental Science, State Evironmental Protection Administration of China , Nanjing 210042

\begin{abstract}
Exotic weeds have caused serious harm to crop production , orchards , lawns , natural environment and biodiversity in China. This is closely related to certain characteristics of the exotic weeds and to lack of environmental resistance. To manage exotic weeds, measures should be taken in two aspects : one is prevention of introduction of exotic weeds, and the other is control of existing ones. In the former aspect, measures that should be taken include :1) reinforcing plant quarantine ;2) establishing a risk assessment system for introduction of exotic plants, and 3 ) encouraging the utilization of native plants. In the latter aspect, the following comprehensive measures should be taken :1) controlling ecological destruction ;2) conducting biological control of exotic weeds ;3) using economic plants as habitat displacement control agents, and 4 ) conducting utilization of exotic weeds.
\end{abstract}

Key words : exotic weeds, harmfulness, weed management, strategy

\section{1 引言}

入侵的外来杂草除了受自身生物学特性和地域 生态因素影响外,由于环境阻力的缺乏或较弱,其发 生发展的速度是本土杂草所无法相比的，因此可造 成严重的危害。截止到现在,中国已被研究记载的 较常发生的外来杂草共有 76 属, 108 种。其中属于
恶性杂草的有 1 种, 属于区域性恶性杂草的有 14 种, 属于常见杂草的有 8 种, 其余为一般性杂草 (强 胜, 曹学章, 2000)。外来杂草已成为我国杂草区系 的重要组成部分。随着经济的发展、科学技术的进 步和交通的发达，我国与世界各地的联系更加紧密， 这无疑增加了外来杂草传入我国的可能性，现有的 外来杂草也正在国内快速扩散。因此,总结外来杂 
草在我国所造成的危害, 分析其原因并提出相应的 管理对策具有重要的现实意义。

发达国家如美国对外来杂草已有比较系统的研 究工作 种类的统计分析;对其危害程度、范围和方 式的研究; 提出的预防和加强检疫等措施阻止新外 来杂草入侵; 通过检测和监测以控制其传播；清除和 生物防治已有的外来杂草等。不过，就如何对外来 植物的引进进行风险评价还没有提出完整的关键技 术措施的报道（Westbook \& Eplee，1996)，只有有 关结实量大的外来植物会比小的更具危险性的某些 设想 (Richardson,1996)。国内就中国外来杂草的 调查研究及其防除的报道已有很多, 不过大体集中 在 4 种属检疫杂草以及豚草 (Ambrosia artemisiifolia)、紫茎泽兰 (Eupatorium adenophorum)、凤眼莲 (Eichhornia crassipes)、空心莲子草 (Alternanthera philoxeroides) 等少数种类上。针对外来杂草的种 类、来源地、危害及原因、管理对策等进行总体分析 的报道极少（丁建清，王韧，1998），所涉及的外来杂 草种类也不够全面。本文在这些研究的基础上，结 合我们自己的多年研究工作, 就更广泛的中国外来 杂草的危害性、发生原因以及管理对策等进行扼要 的概述，特别提出了将植物总体的延续能力作为风 险评价的关键性指标。

\section{2 外来杂草在中国的危害性}

\section{1 对农作物生产的危害}

空心莲子草已经成为中国的一种恶性杂草, 危 害水稻以及秋熟旱作物如大豆、玉米、棉花和烟草 等现有的化学除草剂中仅有很少的几种对其有效， 而且使用适期受到严格限制，特别是作物生长期间 多不宜使用。其地下的根状茎和肉质直根较难清 除、除草剂的作用甚微。发生严重的田块可致作物 颗粒无收，而彻底清除需耗费很大的人力和物力，有 时不得不弃耕。空心莲子草在我国的发生分布和危 害范围广泛, 南从整个华南, 北至华北平原地区, 东 从华东直至西南的广大区域都有。

反枝苋 (Amaranthus retroflexus)、坡果苋 (Amaranthus viridis)、胜红蓟 (Ageratum conyzoides)、野塘 蒿 (Conyza bonariensis)、小飞蓬 (Conyza canadensis) 对秋熟旱作物亦有较大的影响,发生分布和危害范 围亦相当广泛。刺苋 (Amaranthus spinosus) 则对夏 秋季蔬菜危害严重。
毒麦 ( Lolium temulentum)、裸柱菊（Soliva anthemifolia)、波斯婆婆纳 (Veronica persica) 危害冬季 作物小麦和油菜 (李扬汉, 1965)。波斯婆婆纳是一 种长江流域和华北地区的区域性恶性杂草, 繁殖力 强, 防除较为困难, 因而危害性较大(强胜, 李扬汉, 1990 ;李扬汉, 1998)。由外来杂草对农作物生产造 成的危害面积达 486 万 $\mathrm{hm}^{2}$, 防治面积 350 万 $\mathrm{hm}^{2}$, 防除的投入 5.3 亿元，未防治面积上导致农产品的 损失 71 万吨, 每年的经济损失已超过 15 亿元 (中国 农业年鉴编辑委员会, 1999)。

\section{2 对果园的危害}

一年蓬 (Erigeron annuus) 、小飞蓬、野塘蓠是果 园发生危害严重的杂草。一年蓬于春夏之交常形成 单优杂草群落, 并构成明显的景观; 小飞蓬和野塘䒾 于夏秋季形成优势群落。它们对果园的土壤结构和 肥力影响很大, 若不及时防除, 果树产量大减, 甚至 会使整个果园荒废。这些杂草的分布范围几乎遍及 全国的大部分地区(李扬汉,1998)。

胜红蓟、紫茎泽兰、飞机草 (Eupatorium odoratum) 是热带和南亚热带果园的主要杂草 (李扬汉, 1998)。

\section{3 对草坪的危害}

近年来, 国内草坪的面积不断扩大, 但杂草入侵 引起草坪的退化问题未能很好解决。在危害草坪的 杂草中，外来杂草占了极大的比重。

据对南京地区的草坪杂草调查发现，引起草坪 严重退化的杂草有三叶草 [ 白三叶草 (Trifolium repens) ]。该草在冬季常绿, 并仍然保持一定的生长; 春季当南京地区大多数暖性草坪草处于枯黄休眠季 节时, 它们乘虚而入, 讯速生长并很快蔓延开来; 待 春夏之交草坪草萌生时正是三叶草生长的最盛时 节, 草坪草的生长受到严重阻碍。北美车前 (Plantago virginica) 侵入草坪, 也会使草种生长抑制和草 坪退化, 并单独成为纯群。此外, 直立婆婆纳 $(V e-$ ronica arvensis)、细叶芹 (Apium leptophyllum)、北美 独行菜 (Lepidium virginicum) 、空心莲子草、小飞篷、 野塘蓠也是草坪上的常见杂草, 有时危害也相当严 重( 强胜, 李广英, 2000)。

\section{4 对环境的影响}

全国除了西北地区外，由北至南，从东到西，外 来杂草几乎已经改变了道路、宅旁、撂荒地、裸地的 景观; 春夏之交，一年蓬白色的头状花序构成了白色 
的景观;夏秋季由小飞蓬、野塘蒿形成黄绿或灰绿 色，秋冬季变成枯黄色的景观。近 10 年来，豚草分 布在城市周围，取代小飞蓬和野塘蓠，构成了绿色和 黄绿色的新景观。紫茎泽兰和飞机草则在西南地区 形成景观（强胜,1998a）。胜红蓟和飞机草也在华 南地区有类似的影响和效应。

空心莲子草在我国东部也构成了绿色水面的景 观，在华南和西南，凤眼莲也覆盖了水面。

在豚草的发生地, 空气中会漂浮大量豚草花粉, 能引起过敏者产生哮喘，眼、耳、鼻奇痒，喷德流泪和 流涕等 枯草热病” 病症, 严重者导致死亡。每年大 约有 $1 \%$ 的人群有不同程度的反应(夏风云等， 1985 ;李明震等, 1997 杨畑等, 1997)。

\section{5 对本土生物多样性的影响}

外来植物与本土植物竞争养分、水分、阳光等, 影响本土植物的生长并影响生态系统的结构和功 能。而随着本土植物区系、生态系统结构和功能的 改变, 原有动物的生存条件也将恶化。因此外来植 物的引入在丰富了中国植物区系成分和植物群落类 型的同时，对我国的本土生物多样性却产生了不利 影响。道路旁、闲置地和暂时性裸地几乎都成了以 外来杂草为优势种的植物群落类型的主要发生地, 豚草、小飞蓬、野塘蓠、一年蓬、飞机草、紫茎泽兰、胜 红蓟等都能以单优或共优的形式构成群落 (万方 浩,王韧, 1990; 万方浩,关广清, 1993; 刘伦辉等, 1985 ;Auld \& Martin ,1975)。飞机草、紫茎泽兰、胜 红蓟等主要发生分布于西南以及华南的热带和亚热 带地区; 豚草、小飞蓬、野塘蓠、一年蓬则主要在亚热 带和温带地区。

根据对浙江水稻田埂植物多样性调查研究表 明, 在以本土高秆植物白茅 (Imperata cylindrica var. major)、狼尾草 (Pennisetum alopecuroides) 为优势种 的水稻田埂植物群落中, 共有植物 15 科 26 属 26 种, 物种多样性指数为 0.7095 ; 以本土矮秆植物马 唐 (Digitaria sanguinalis)、稗 (Echinochloa crusgalli) 为优势种的水稻田埂植物群落中, 共有植物 21 科 36 属 39 种,物种多样性指数为 0.9383 ; 而在以外来 杂草空心莲子草为优势种的水稻田埂植物群落中， 共有植物 8 科 13 属 13 种, 物种多样性指数只有 0.6393 。空心莲子草已构成了对水稻田埂植物生物 多样性的严重威胁, 空心莲子草侵入处植物种趋于 单一, 其他植物种数显著减少, 植被景观单调。伴之
大量病虫天敌减少,作物病虫害加重 (余柳青等, 1997 )。

凤眼莲原产南美, 大约于 20 世纪 30 年代作为 畜禽饲料引入我国推广种植, 后逸为野生, 迅速扩 散、现广泛分布于我国南方省区, 严重威胁到其他水 生生物的生存。云南滇池约有 10 余平方公里的水 面被凤眼莲所覆盖, 盖度达 100\% , 群落多样性几乎 为 0 。由于凤眼莲的排挤, 滇池原有的十多种水生 植物已相继灭绝, 而原有水生植物的灭绝又影响了 水生动物的生存, 水生动物由 60 年代以前的 68 种 减少了一半,鱼类从 15 种降至 5 种( 丁建清等, 1995 ;丁建清, 王韧, 1998)。

\section{3 外来杂草的潜在危害性}

许多杂草的潜在危害性更大。在中国的外来杂 草中, 具有较大潜在危险性的杂草有如下种类。

\section{1 紫茎泽兰}

紫茎泽兰原产美洲墨西哥至哥斯达黎加，具较 强的侵染力和竞争力, 有发达的茎和根并能产生大 量的子实，一旦定植很难清除。可以侵占大片的农 田、果园、稀疏森林、草地、路边和间隙空地等, 对农 作物和经济植物的生产、森林更新及草地的维护有 极大的影响, 对马具毒性, 对牛有拒食性( 强胜, 1998a)。紫茎泽兰带有冠毛的子实极有利于传播扩 散，于本世纪中期由泰国、缅甸传入中国云南，现广 布于西南的云南省以及贵州、西藏、广西和四川的局 部(刘伦辉等,1985 赵国晶, 马云萍，1989）,并正以 每年大约 $60 \mathrm{~km}$ 左右的速度向东、向北蔓延扩散 (向业勋,1991)。据此估计, 金沙江中下游沿岸、贵 州东部、广西南部广大地区将会受到它的侵染和危 害。依紫茎泽兰对气候条件的适应性,完全可能入 侵整个长江以南各省区 (赵国晶, 马云萍, 1989; 强 胜, 1998a)。

\section{2 飞机草}

飞机草原产美洲。由于种子和地下根茎均可繁 殖, 繁殖力和竞争力都很强, 形成成片的群落, 危害 性较大。现在海南、广东和云南省有分布。在云南 常和紫茎泽兰混生危害(赵国晶, 马云萍,1989)。 其潜在的危害性在于有继续向北扩展分布范围的可 能性。

\section{3 豚草 (艾叶破布草)}

豚草原产北美洲 现已在美国、加拿大、前苏联、 
日本等约 20 个国家有分布和危害。20 世纪 $40 \sim 50$ 年代传入我国，现已在以辽宁、黑龙江、吉林、山东、 湖南、湖北、江苏、浙江、安徽、江西、上海等省市的大 中城市为中心，沿交通线向四周扩散、蔓延。豚草的 繁殖力较强, 子实存活率高, 植株竞争力强, 生长中 排斥其他植物及杂草, 很快形成优势。对作物、牧 草、景观危害性较大 (万方浩, 关广清,1993)。在原 产地美国，豚草出现在玉米、大豆、烟草和马铃薯等 地中，对它们的产量有显著的影响。植株的营养价 值较低, 而且含苦味物质和香精油, 牲畜拒食, 偶尔 为奶牛所食, 奶制品中含有不佳的味道。因此, 前苏 联、澳大利亚和罗马尼亚等国将其列为检疫对象, 美 国和加拿大将其列入有害杂草名单（黄宝华， 1985 )。

\section{4 三裂叶豚草 (大破布草) (Ambrosia trifida)}

三裂叶豚草原产北美,50年代传入我国辽宁 省，以沈阳、铁岭为中心, 沿交通线四处蔓延, 也已在 黑龙江、北京发现。其植株高大，分布范围和适应性 与豚草相似，很有可能继续向南扩散。

\section{5 毒麦 (Lolium temulentum)}

毒麦原产地中海地区, 现广泛分布于亚、非、美、 澳洲的 38 个国家和地区。在中国 现已在 20 多个 省、市、自治区发现。主要混杂在麦种中传播扩散。 毒麦子实皮下含神经毒素——毒麦碱（Temuline， $\left.\mathrm{C}_{7} \mathrm{H}_{12} \mathrm{~N}_{2} \mathrm{O}\right)$, 它是由真菌 Stromatinia temulenta 寄生 于子实糊粉层产生的,当人、畜、禽食用了含毒麦的 小麦或面粉,可能引起头晕、恶心、呕吐、昏迷、痉挛 等症状(李扬汉，1965)。

3.6 假高粱（约翰逊草，阿拉伯高粱）（Sorghum halepense )

假高粱原产地中海地区，现已广布于世界热带 和亚热带地区，包括欧洲 11 个国家、亚洲 16 个国家 和地区、非洲 4 个、美洲 18 个国家以及大洋洲诸国。 我国已在华南、华东以及西南部分省份的大中城市 周围有发现, 尚分布不广。不过有蔓延趋势。

假高粱繁殖力极强，生长迅速，对作物的危害性 极大, 防除十分困难。牲畜如大量摄食, 消化过程中 会引起氢氧酸在牲畜体内的累积, 导致中毒。故被 列为检疫对象。此外, 美国、澳大利亚等亦将其列为 检疫杂草。

\section{7 薇甘菊 (Mikania micrantha)}

薇甘菊原产于中、南美洲, 现已扩散至南亚、东
南亚及亚洲太平洋地区的多个国家。是一种攀援植 物, 繁殖能力和生命力极强, 人工拔除斩草”不能 “除根”, 即使火烧后有一点青色的根茎留在地里, 很快就会萌生。60 年代被引入印尼植物园用于橡 胶园的地面覆盖,由于当地适宜的气候和土壤条件， 很快在印尼、马来西亚、菲律宾、泰国等地蔓延开来， 给种植香蕉、茶叶、可可、水稻等经济作物的农民造 成了重大损失。所到之处, 像被子一样包裹树木, 覆 盖花草, 受其侵害的植物或者被绞杀、重压致死, 或 者因缺少阳光、水分, 不能进行光合作用而枯萎。被 称为 植物杀手”。

最初传入我国的报道是在香港, 现正在广东省 猖狂蔓延, 深圳是受薇甘菊侵害的重灾区, 受害面积 超过 $2700 \mathrm{hm}^{2}$ 林荫道、公园、自然保护区都发现了 薇甘菊。在深圳梧桐山、仙湖植物园、深圳水库周围 等生态敏感区, 薇甘菊危害发生率甚至已经达到 $60 \%$ 。在生态环境相对独立的内伶仃岛，纵向从海 拔 $6 \mathrm{~m}$ 至 $160 \mathrm{~m}$ 的范围内都有它的踪迹, 横向 $40 \%$ 至 $60 \%$ 的地区几乎都被它覆盖。继深圳大面积受 灾之后, 珠海、广州等地相继发现薇甘菊入侵 (孔国 辉等 2000 )。

在现有的外来杂草中, 完全可能还有具潜在危 险性的杂草种，只是至今我们对其仍然没有充分的 认识。所以, 加强对外来杂草的生物生态学特性的 研究并严密监视其发生和发展规律是非常必要的。

\section{4 外来杂草在我国发生危害的原因}

外来杂草之所以能在中国发生和危害, 甚至有 些会呈爆发性的扩展和发生, 这与它们所具有的某 些特性和环境阻力缺乏密切相关。

\section{1 环境阻力缺乏导致的失控}

外来植物或杂草在原生区域环境中, 其生长发 育和繁殖都受到周围环境特别是它的自然天敌 病菌、昆虫和其他草食性动物等的制约。一旦这些 植物传到新的地区，这些制约因子通常就消失了。 外来的植物在新环境中足够的环境阻力特别是生物 阻力 (自然天敌生物) 出现之前, 个体数量将会持续 不断增长, 这就使其繁殖的后代按几何级数增加, 最 终爆发生态危机 (顾德兴 ,1988)。

此外，任何植物区系中都包含有因自然选择而 逐渐适应于特定生态小生境的植物, 但也存在一些 未被占满的小生境, 所以外来种就可能利用这一 
生态真空” 取得立足之地, 这也是外来杂草在新定 植地能拥有较为宽松环境的一个原因。许多外来杂 草都成为次生裸地和人为干扰频繁的生境的先锋植 物, 其原因也在于此。

\section{2 外来杂草的强异株克生作用}

一些外来杂草一旦侵入某种生境, 会很快形成 单优势群落, 这与它们具有异株克生作用特性, 从而 能在竞争中处于优势地位密切相关。紫茎泽兰根部 会分泌异株克生化合物，抑制个体周围生长的其他 植物的生长发育, 能明显降低白三叶草和酸模 (Rumex nepalensis) 的种群数量 (Tripathi et al. , $1981)$ 。其植株的水和乙醚提取液对植物种子萌发 和幼苗生长抑制率可高达 100\%（赵国晶，马云萍， 1989 ;Angiras et al.,1988; 1989; 和爱军,刘伦辉， 1990 ) ,并且其效应随浓度增高而增强 ( Tripathi et al. , 1981 ;Yadav \& Tripathi ,1984)。

豚草的 $10 \%$ 叶水提取液对画眉草 (Eragrostis pilosa)、稗草 (Echinochloa spp.)、红三叶草 (Trifolium pratense)、野胡夢卜和反枝苋等杂草以及数种作 物的种子萌发有明显的抑制作用（Bradow，1984）。 豚草的异株克生化合物主要有肉桂醇、豚草酚 ( Watanaba \& Idko，1981）、聚乙炔、倍半萜烯、豆甾醇、 $\beta-$ 谷甾醇混合物 (Fischer \& Quijano,1984)、绿五酸和 咖啡酸 (Rice, 1968)。豚草作为先锋植物, 这一异株 克生作用在植物群落演替中起了重要的作用(王大 力, 1995)。被发现具有异株克生作用的外来杂草 还有:反枝苋(Bhowmik \& Doll，1982)、北美独行菜 (马永清等，1991）、一年蓬、小飞蓬（马永清等， 1991 ; Kobayashi et al. ,1980)、胜红蓟(韦琦等， 1997 ) 等。

\section{3 传粉生态特性}

当一种杂草的个体被传播到远离其原产地的新 环境时,由于该个体脱离其种群, 通常缺少异体传粉 及受精的外在条件,故具有自花受粉或无性繁殖力 是其必然的选择性状。紫茎泽兰是一种无融合生殖 的三倍体 $(n=17)$, 植物通常形成无配子种子 ( Holmgren, 1919;Baker,1965;Auld ,1970)。北美车 前具风媒型和闭花受精型两种类型花, 前者花的雄 惢长度为雌蕊的 2 倍左右, 花丝细长, 花药丁字型着 生, 雌荵先熟,并且从没开放的花冠中伸出羽毛状柱 头, 之后花开, 雄惢成熟, 并远远伸出花冠之外, 果时 花瓣反折;而后者的雌惢长雄惢短，花药仅处于羽毛
状柱头的 $1 / 2$ 处, 整个花期花冠始终闭合, 雄蕊不伸 出花冠, 果时花瓣也不反折, 这是一种较为典型的闭 花授粉花。据郭水良 (1995) 的调查研究, 北美车前 闭花传粉占绝对优势, 但其比例受种群密度的影响。 种群密度较小和较高时, 闭花传粉的比例最高; 种群 处于中等密度, 则风媒异花传粉的比例高。总之, 北 美车前以自花授粉为主, 使其在不利条件下能产生 大量种子, 同时又有一定比例的风媒异花传粉, 保证 了后代具有较为丰富的变异, 从而适应于多样的外 界环境条件。

\section{5 外来杂草的管理对策}

外来杂草已在我国产生了严重的危害,而其潜 在的危害性更大。因此, 加强对外来杂草的管理已 显得十分必要和迫切。

外来杂草的管理包括两个方面，一是防止引进 可在我国造成危害的杂草种类，二是对已在我国分 布和发生危害的种类采取有效的防除措施, 控制或 消除其危害。

\section{1 防止外来杂草引进的措施}

防止引进是实现对外来杂草危害控制的首选方 法。外来杂草的引进方式包括作为有用植物而引进 (有意引进) 和随交通工具、进口农产品等而传入 (无意引进), 前者如空心莲子草、凤眼莲、三叶草等 的引进, 后者如紫茎泽兰、飞机草、假高粱等的引进。 对这两种不同方式的引进需要采取不同的管理方 法。对无意引进的管理主要是加强检疫; 而对有意 引进的管理主要是进行预引种审查 ( 风险评价), 即 评价外来植物引进后可能造成的危害, 以及在利用 这种植物的效益和代价 (包括长期影响)之间寻求 正确的平衡，并适当考虑不确定性。

1 ) 加强植物检疫。建国以来, 我国的动植物检 疫事业发展很快，《动植物检疫法》于 1995 年正式 颁布实施, 全国现有动植物检疫机构 180 余个,已形 成遍布全国各地的监管网络。几十年来, 植物检疫 对防止检疫杂草和一些有害杂草的传入起到了积极 的作用。例如, 从 1986 年 1990 年 9 月, 仅就从上 海口岸进口的 349 船次的粮食中, 就有 46 船次截获 毒麦和假高粱子实, 此外, 还截获其他杂草子实 30 科 100 余属 200 余种 ${ }^{(1)}$ 。 
贸易的发展和国际往来的日益频繁, 必然增加 外来杂草无意引进的可能性，因此必须切实加强植 物检疫, 将有害植物特别是在原产地就是杂草的植 物的繁殖体阻挡在国门之外。在植物检疫中, 不仅 要盯住目前我国列入检疫对象的四种属类的杂草 [菟丝子属（Cuscuta spp.）、列当属（Orobanche spp. )、假高粱、毒麦]，对其他检出的杂草种子也应 给予足够的重视, 特别是那些在原产地为恶性杂草、 而在我国尚无分布的植物。

2 ) 建立外来植物引种驯化的风险性评价制度。 植物检疫的实施并不能完全控制外来杂草的引进。 许多外来杂草是作为有用植物引进而后归化的, 最 典型的例子是空心莲子草。由此可看出盲目引进植 物所具有的潜在危险性。防止这种悲剧再次发生的 唯一途径, 就是以谨慎的态度去看待引进工作, 不要 只看到眼前利益。建立植物引种的风险性评价制度 十分必要。

风险性评价应包括风险分析和风险控制两方面 的内容。前者包括引种植物的潜在危害性识别、物 种繁育及其演变能力的识别和生态风险识别特别是 与气候和生境 (土壤、天敌生物等) 相关性限制因子 的分析识别等 (万方浩等, 1997; 李鸣, 秦吉强， 1998 )。其中物种繁育能力与气候、生境等相关限 制因子的分析对判断引种植物的风险性至关重要。 同属于人工生境条件下的栽培植物与杂草植物的一 个本质区别，就是前者在人工生境条件下的延续需 要人的干预, 而后者则能在人工生境条件下自行繁 育并不断延续。显然, 如果一种植物在栽培的过程 中脱离了人们的栽培过程和环节 (人工干预) 仍然 能自然繁衍, 这就成了杂草, 即所谓的逸为野生, 就 具有了现实的或潜在的危险性。而且这种危险性的 大小是直接与该植物在人工生境中的自然延续能力 成正比的。延续能力越强的植物，在人工生境中的 数量就会越多，对资源和空间的侵占就越多，对人类 带来的危害性就越大。如果该植物又直接或间接影 响到人、畜的生命安全或对作物构成巨大的影响，如 豚草、紫茎泽兰和假高粱等, 则其危害性就更大。因 此, 观察一种引进植物最关键的和最重要的标准, 就 是该物种的繁育能力和与气候生境限制因子共同作 用而构成的该植物的自然延续能力, 对自然延续能 力强的植物种的引进应慎重。相反, 对无自然延续 能力或自然延续能力弱的植物种的引种可以在有控
制的条件下进行。

不过, 最终是否引进该种植物, 还需要经过风险 控制程序。该程序是对引进植物可能带来的负效应 和正效应 (经济受益) 进行分析比较以及对引进过 程中是否有有效的控制措施及风险监控的方法进行 综合评价，给出一个客观公正的评价, 最终作出批准 或否决引进的决策。建立一个专门的外来生物引种 机构，统一管理以及颁布外来生物引种利用法规是 十分必要的( 万方浩等,1997)。

3 ) 鼓励利用本土植物。积极鼓励在可能的情 况下利用本土植物物种作花卉、草坪、牧草、自然保 护及其他经济用途, 以减少外来种的引入。

\section{2 外来杂草的防除措施}

对于已经在我国分布和发生危害的外来杂草种 类,需要采取综合的防除措施。

1) 防治生态破坏。许多外来杂草具有先锋植 物的特征, 多首先入侵裸地、间隙裸地、撂荒地、耕作 和农作间隔时间长的农田、果园、人工干扰频繁的路 边和宅旁。所以, 应切实加强植被保护, 防止滥毁原 生植被。在裸地和间隙裸地、路边和宅旁等应及时 复植草坪、林木和花卉等有用植被, 阻止外来杂草乘 虚而入 将濒于退化的农田、草场和其他生态系统恢 复到一个健康和高产的状态。

2 ) 开展外来杂草的生物控制。外来杂草之所 以会在新区猖獗, 其主要原因之一是缺少自然天敌 的制约。从原产地引进该草的自然天敌, 在进行安 全性、专一性、生态适应性等一系列研究的基础上释 放，以达到生态控制外来杂草危害的目的，这就是生 物控制的方法。在国外, 利用这种经典生物控制的 技术已在许多外来杂草的控制上获得成功，如澳大 利亚对原产欧洲的灯芯草粉苞苣 (Chondrilla jun$c e a$ )、原产南美的仙人掌 (Opuntia inermis \& O. stricta) 和原产巴西的槐叶萍 (Salvinia molesta) 的控制， 美国对原产欧洲的鹿香飞廉 (Carduus nutans) 和原 产巴西的空心莲子草的控制等 (强胜 ,1998b)。

我国从 80 年代以来, 也分别开展了通过引进泽 兰实蝇 (Procecidochare utidis) 控制紫茎泽兰 (张智英 等,1988) , 用空心莲子草跳甲 (Agasicles hygrophila) 防治空心莲子草, 豚草条纹叶甲 (Zygogramma suturalis) 防治豚草( 万方浩, 王韧, 1990) 等研究, 并实施 了定点释放。此外, 凤眼莲的生物防治研究也在开 展( 丁建清等,1995)。 
利用真菌防除外来杂草的研究工作也正在开 展。例如，利用飞机草线孢菌 (Mycovellosiella eupatorii-odorati) 防治紫茎泽兰和利用链格狍菌 (Alternaria alternata) 作为生物除草剂防治紫茎泽兰的研究工 作也取得了初步的乐观的研究结果 (杨宇容, 郭光 远 ,1991; ;iang \& Summerell, 1999; 强胜,1998a ; 郭 光远等,1991)。

不过，上述引进生物天敌的工作也存在较大的 生态风险, 天敌在取食目标杂草的同时也可能会侵 害其他植物。

3 ) 利用经济植物进行生境替代控制。在外来 杂草侵染地区，利用经济植物的生境替代控制，也是 减轻危害的重要途径。在云南, 通过种植木豆 ( $C a$ janus cajan），利用其快速生长、形成密丛的特点，阻 止了阳生性的紫茎泽兰发生和生长, 而生长的木豆 可放养紫胶虫 (Laccifer lacca) , 还可收获木豆种子 (余宇平等,1988)。黑麦草 (Lolium perenne) 亦是可 以选择作为替代的种类。许多造林树种如云南松 (Pinus yunnanensis)、蓝桉(Eucalyptus globulus) 等恢 复造林, 也是很有效的替代选择( 何大愚, 刘伦辉, 1988 )。对豚草的控制亦可采取类似的措施。

4 ) 开展对外来杂草的利用。对已发生的外来 杂草进行利用也是一种化害为利的防治方法。比 如, 利用外来杂草具有较强的入侵裸地并迅速形成 植被覆盖的特点，对保持水土有重要意义。胜红蓟 所具有的异株克生的特性正被研究用于控制其他杂 草, 甚至可模拟其结构合成新的除草剂品种。豚草 可做为鹋鹑的饲料，豚草子实炸油可做油漆等。紫 茎泽兰也正被利用来制作纤维板和沼气等 (江蕴华 等 ,1997)。

\section{6 结语}

外来杂草已在我国造成了严重危害, 外来杂草 问题已成为我国一个重要的环境问题。随着我国与 世界各地贸易、旅游等活动的增加，这一问题在将来 可能会变得更加严重。因此, 应对其给予特别的关 注, 尽早采取措施，对付外来杂草的入侵。在防止引 进外来杂草方面,除加强检疫, 防止外来杂草无意传 入外，对作为有用植物引进的外来植物，应建立外来 植物引进的风险化评价制度。对已传入国内的外来 杂草，应采取综合的防治技术，控制或消除其危害。

\section{参考文献}

丁建清, 王韧, 范中南, 陈志群, 付卫东, 1995. 恶性水生杂草 水葫芦在我国的发生、危害及其防治策略. 杂草学报, 9 (2) : $49 \sim 52$

丁建清, 王韧, 1998. 外来种对中国生物多样性的影响. 见: 《中国生物多样性国情研究报告》编写组 (编), 中国生 物多样性国情研究报告. 北京: 中国环境科学出版社, $58 \sim 61$

顾德兴, 1988. 杂草的发生和演替. 自然杂志, 10(8) : 614 616

郭光远, 马俊, 杨宇容, 刘勇, 徐丽华, 姜成林, 1991. 国内新 病害——紫茎泽兰叶斑病原菌的研究. 植物病理学报, 21(4): $245 \sim 250$

郭水良, 1995. 外域杂草的产生、传播及生物与生态学特性 的分析. 广西植物, 15(1): 89 95

和爱军, 刘伦辉, 1990. 紫茎泽兰浸提液对几种植物发芽的 影响. 杂草学报, 4(4): 35 38

何大愚, 刘伦辉, 1988. 紫茎泽兰防治研究进展. 生态学进 展, 5(3): $163 \sim 168$

黄宝华, 1985. 豚草在国内的分布及危害调查. 植物检疫, 1985, (1) : $62 \sim 65$

江蕴华, 张无敌, 余晓华, 赵凡, 1997. 紫茎泽兰. 见: 史志诚 (主编), 中国草地重要有毒植物. 北京: 中国农业出版 社, $124 \sim 139$

孔国辉, 吴七根, 胡启明, 叶万辉, 2000. 薇甘菊 (Mikania micrantha H. B. K. ) 的形态、分类与生态资料补记. 热带亚 热带植物学报, $8(2): 128 \sim 130$

李明震, 柳小梅, 杨炣, 钟立厚, 曹作炎, 1997. 武汉市武昌地 区气传致敏花粉调查研究. 武汉植物学研究, 15(1): 66 $\sim 72$

李扬汉, 1965. 毒麦及其变种籽实分类的研究. 植物保护学 报, $4(1): 43 \sim 48$

李扬汉 (主编), 1998. 中国杂草志. 北京: 中国农业出版社 李鸣, 秦吉强, 1998. 有害生物危险性综合评价方法的研究. 植物检疫, 12(1): 52 55

刘伦辉, 谢寿昌, 张建华, 1985. 紫茎泽兰在我国的分布、危 害及防除策略的探讨. 生态学报, 5(1): 1 6

马永清, 刘德立, Lovett J V, 1991. 杂草间的他感作用及其在 杂草生防中的应用. 生态学杂志, 10(5): 46 49

强胜, 1998a. 世界性恶性杂草一一紫茎泽兰研究的历史及 现状. 武汉植物学研究, 16(4) : 354 360

强胜, 1998b. 生物除草剂研究的历史、现状及展望. 见: 程登 发 (主编), 植物保护 21 世纪展望. 北京: 中国科学技术 出版社, $89 \sim 97$

强胜, 曹学章, 2000. 中国外来杂草的考察与分析. 植物资源 与环境学报, 9 (4) : $34 \sim 38$

强胜, 李广英, 2000. 南京市草坪夏季杂草分布特点及防除 措施研究. 草业学报, 9(1) : 48 54

强胜, 李扬汉, 1990。安徽沿江圩丘农区夏收作物田杂草群 落分布规律的研究. 植物生态与地植物学学报, 14(3): $213 \sim 219$

余宇平, 梁家社, 何大愚, 1988. 紫茎泽兰防除方法的进展. 杂 草学报, 2(2): 39 40

万方浩, 关广清, 1993. 豚草及豚草综合治理. 北京: 中国科 
学技术出版社

万方浩, 王韧, 1990. 豚草生物防治概况. 杂草科学, 22: 30 32

万方浩, 王韧, 1990. 恶性害草豚草的生物学及生态学特性. 杂草学报, 4(1): 45 48

万方浩, 叶正楚, Harris P, 1997. 生物防治作用物风险评价的 方法. 中国生物防治, 13(1):37 41

王大力, 1995. 豚草属植物的化感作用研究综述. 生态学杂 志, 14(4) : $48 \sim 53$

韦琦, 曾任森, 孔垂华, 骆世明, 曾强, 谭惠芬, 1997。胜红蓟 地上部化感作用物的分离与鉴定. 植物生态学报, 21 (4) : $360 \sim 366$

夏凤云, 张友芹, 高晶, 1985. 沈阳地区豚草花粉症探讨. 中 华耳鼻咽喉科杂志. 20(1):21 22

向业勋, 1991. 紫茎泽兰的分布、危害及防除意见. 杂草科 学, 5(4): 10 11

杨畑, 李耀华, 鲜云艳, 李明霞, 1997. 武昌地区豚草花粉症 研究. 武汉植物学研究, 15(3):281 282

杨宇容, 郭光远, 1991. 飞机草菌线孢菌对紫茎泽兰生长及 生理影响的研究. 杂草学报, 5(1):6 11

余柳青, 陆永良, 徐青, 黄世文, 王鸣遥, 渡边泰, 根本正之, 1997. 稻田畦畔和灌溉沟渠植物的多样性研究. 见: 强 胜 (主编), 农业植物学学术研讨会论文集, 59 62

张智英, 魏艺, 何大愚, 1988. 泽兰实蝇生物学特性的初步研 究. 生物防治通报, 4(1): 10 13

赵国晶, 马云萍, 1989. 云南省紫茎泽兰的分布与色害的调 查研究. 杂草学报, 3(2):37 40

中国农业年鉴编辑委员会, 1999.中国农业年鉴 1999。北 京: 中国农业出版社, 448 456

Angiras N N, Singh S D and Singh C M, 1988. Allelopathic effects of weeds on germination and seedling growth of maize and soybean. Indian Journal of Weed Science, 20 (2) : $82 \sim 87$

Angiras N N, Singh S D and Singh C M, 1989. Allelopathic effects of some weeds on germination and growth of chickpea (Cicer arietinum L. ). Indian Journal of Weed Science, 21( 1 ) : $85 \sim 87$

Auld B A, 1970. Eupatorium weed species in Australia. Pestological Article and News Summery, 16(1): $82 \sim 86$

Auld B A and Martin P M, 1975. The autoecology of Eupatorium adenophorum Spreng. in Australia. Weed Research, 15: $27 \sim 31$

Baker H G, 1965. The modes of origin of weeds. In: Baker H G and Stebbins G L (eds.), The Genetics of Colonizing Species, New York: Academic Press, $147 \sim 168$

Bhowmik P C and Doll J D, 1982. Corn and soybean responses to allelopathic effects of weed and crop residues. Agronomy Journal, 74: $601 \sim 606$

Bradow J M, 1984. Germination regulation by Amaranthus palmerri and Ambrosia artemisiifolia. In: Joan M C (eds.), The Chemistry of Allelopathy, Biochemical Interations Among Plants, Washington, DC: American Chemical Society, 268: $285 \sim 299$

Fischer N H and Quijano L, 1984. Allelopathic agents from common weeds: Amanrathus palmer, Ambrosia artemisiifolia and related weeds. In: Joan M C (eds.), The Chemistry of Allelopathy, Biochemical Interations Among Plants, Washington, DC: American Chemical Society, 268: 133 147

Holmgren I, 1919. Zytologisch Studien uber die Fortpflanzung den Gattungen Erigeron und Eupatorium. Kegel Svenska Vetenskapskadich Handlich, 59: $1 \sim 117$

Kobayashi A, Morimoto S, Shibata Y, Yamashita K and Numata $\mathrm{M}, 1980 . \mathrm{C}_{10}$-polyacetylenes in early stages of secondary succession. Journal of Chemistry Ecology, 6(1): 119 131

Qiang S and Summerell B A, 1999. Pathogenicity of Alternaria alternata on crofton weed (Eupatorium adenophorum). In: Proceedings of the 17th Asian-Pacific Weed Science Society Conference. Bangkok: The Organization of the 17th AsianPacific Weed Science Society Conference, $345 \sim 347$

Rice E L, 1968. Inhibition of nodulation of inoculated legumes by pioneer plant species from abandoned fields. Bulletin of the Torrey Botanical Club, 95(4): $346 \sim 358$

Richardson D M, 1996. Forestry trees as alien invaders: the current situation and prospects for the future. In: Sandlund O T, Schei P J and Viken A (eds.), Proceedings of the Coference on Alien Species, Trondheim, Norway, $127 \sim 134$

Tripathi R S, Singh R S and Rai J P N, 1981. Allelopathic potential of Eupatorium adenophorum: a dominant ruderal weed of Meghalaya. In: Proceedings of India National Science Academy, B, 47(3): $458 \sim 465$

Watanaba S and Idko T, 1981. Growth and germination inhibition in hog-weed. Agricultural Biology Chemistry, 45(12): $2919 \sim 2920$

Westbrooks R and Eplee R E, 1996, Strategies for preventing the world movement of invasive plants. In: Sandlund O T, Schei P J, Viken A( ed.), Proceedings of the Conference on Alien Species, Trondheim, Norway, $148 \sim 154$

Yadav A S and Tripathi R S, 1984. Effect of associated species on 3 Eupatorium species. Indian Journal of Ecology, 11 (2) : $190 \sim 196$ 